larly been associated with declining birth rates and unless the population explosion can be contained we shall all be undone.

One can perhaps hope that those who have power to plan and decide will, at the least, take into account such facts, predictions and informed guesses as scientists are able to offer. Among other things, they may note the instruction that Deasy puts into these words, "Since the quality of the social and psychological milieu is far more crucial to human performance than the quality of the plumbing-it is clear that the people who know about the planning and the people who know about people should get together."

MARTIN ROTH

\section{Partial Belief}

The Matter of Chance. By H. H. Mellor. Pp. xiii +190. (Cambridge University: London, November 1971.) $£ 4 ; \$ 13$.

According to Kipling there are nine and sixty ways of constructing tribal lays, and every single one of them is right. He might have said the same thing about theories of probability. Mr Mellor thinks that his own view of the subject "makes more sense than its philosophical competitors do of what professional and everyday usage assume to be true of chance". It remains to be seen whether philosophers and statisticians will share his opinion.

A long line of theologians and scientists of a deterministic persuasion have regarded chance as merely a convenient word to describe human ignorance about the causality of situations, something which is unknown to Nature herself. $\mathrm{Mr}$ Mellor does not commit himself very deeply on this issue but he appears to consider chance, if not as a thing in itself, at least as something with which objective reality can be associated. And therein, of course, lies the problem.

At the extreme ends of an almost continuous spectrum of possible views about the nature of probability lie the frequentist, for whom it is a measure of relative frequency of occurrence, and the subjectivist, for whom it is a measure of belief (or some attitude of mind). Mr Mellor rests on what he calls "partial belief" in propositions. This is "a disposition to indulge in publicly describable behaviour, for example, specifically in betting situations". One may leave it to the psychologist or the philosopher to argue whether there is any profound semantic content in such a definition. One may concede that some link between partial belief and behaviour is necessary on the way to a theory in which chance has any kind of objectivity.

The advantage of a subjective view about chance is that it enables us to speak of the probability of a single nonrepeatable event, a point on which the frequentist is in trouble. The disadvantages are in setting up a measure of such probability and in justifying any claims that such a measure has anything to do with the way things happen. Jeffreys took the bull by the horns by postulating that probabilities - or at any rate the kind of probabilities he wanted to talk about-are orderable. More recent attempts to calibrate the probability scale, dating back to Frank Ramsey (and possibly earlier), rely on considering what sort of odds one would accept in a bet on the proposition in question. This procedure is adopted by Mr Mellor.

The idea is attractive but, in my opinion, unsatisfactory. If I am asked to bet on the proposition that there will be a colony on Mars in a hundred years' time I refuse, simply because I shall not be here to collect or to pay up. If I lower my sights and am asked to bet whether there will be a manned station on the Moon in five years' time, I might venture a modest pound, but I certainly would not bet $£ 10,000$, whatever the odds. In fact, if we are to relate probability to the willingness of an individual to accept given odds, we must take account of the size of the stake and his age, and possibly other qualities as well, such as his luck on previous occasions. And in such a case the judgment in probability becomes multidimensional and a single numerical measure is impossible.

Mr Mellor also has a more favour. able view than I about the extent of the agreement which is found among different individuals about the intensity of partial belief in any given case. Anyone who has taken part in an exercise of the Delphi type (in which a group selects a set of contingencies and tries to put probabilities on them) knows what wide divergences of opinion emerge. It is true that such exercises are usually concerned with macro-events such as the probability of an atomic war or the possibility of farming the sea commercially. There would undoubtedly be closer agreement about propositions concerning the fall of dice, the risk of death or indeed any member of a collective of events. But here, I think, the frequentist would rear his head again.

Popper tried to meet one of the difficulties in setting up a probability theory by elevating "propensity" into a basic concept. "Propensity" for $\mathrm{Mr}$ Mellor is a dispositional property. To a simple-minded statistician to say that the chance of a coin coming down heads is one half sounds very like saying that it has a propensity to do so measured by a chance of one half. $\mathrm{Mr}$ Mellor distinguishes between the two. Propensity is a property of the coin. Chance depends both on the coin and the mechanism used for tossing it. This may make for clearer thinking. It is not evident to me that it contributes much to the professional use of statistical probability.

I have a dispositional propensity to a partial belief (quantifiable at about 0.98 ) that we shall not plumb the depths of the foundations of probability until we know a great deal more about how the mind works. In the meantime $\mathrm{Mr}$ Mellor's views are entitled to attention as a serious assault on a very intractable problem.

M. G. KENDALL

\section{Public Enterprise}

Public Enterprise in Practice. By Richard Pryke. Pp. xiii +530 . (McGibbon and Kee: London, 1971.) $£ 6.95$.

THE length and price of this book are likely to deter all but the most ardent students of the nationalized industries. This would be a pity because Mr Pryke has written a very readable, if somewhat controversial, account of the progress of Britain's state industries since their establishment. The study provides a mine of factual and statistical information together with comment and appraisal of the performance of the state sector. It concentrates in particular on productivity and investment of the public sector though there are substantial sections relating to the more important problems faced by particular nationalized industries. It is in no sense an introductory text, however, and many readers may find the course hard going if they have no background knowledge of the subject under discussion.

The study does, however, suffer from some shortcomings. The book is overlengthy given the single objective at hand and that is to prove that nationalized industries are best. Mr Pryke makes every effort to put the best case forward for the public sector industries. His two main conclusions are that they have been technically more efficient than private enterprise and that their operation has not led to any serious misallocation of resources. $\mathrm{He}$ then reasons that "the relationship between good behaviour and public ownership must henceforth be regarded as one of cause and effect". The latter conclusion is certainly debatable and does not follow automatically, but the first two conclusions are not fully substantiated by the analysis. The productivity record of the nationalized industries has been 